\title{
MICOPLASMA COMO CONTAMINANTE DE CULTURAS CELULARES MANTIDAS EM LABORATÓRIOS DE INSTITUIÇŌES PARTICULARES E OFICIAIS
}

\author{
Cosue Miyaki* \\ Michel Marie Pral* \\ Neusa Maria Frazatti Gallina* \\ Edda de Rizzo*
}

\begin{abstract}
MIYAKI, C. et al. Micoplasma como contaminante de culturas mantidas em laboratórios de instituições particulares e oficiais. Rev. Saúde pábl., S. Paulo, 23:39-44, 1989.

RESUMO: Foi realizado estudo sobre a incidência de contaminaçăo por micoplasma em 29 tipos de linhagens celulares pertencentes a sete laboratórios de instituiçoes particulares, oficiais e de ensino superior. Utilizando o método de cultivo direto e oito passagens seriadas em meios específicos, líquido e sólido, verificou-se que, do total de 106 amostras, 48 apresentaram-se contaminadas por micoplasma $(45,28 \%)$, o que constitui elevado indice de contaminaçăo. O fato indica que testes periódicos para a determinaçăo da presença de micoplasma nas culturas em utilizaçăo é recomendável e que as culturas contaminadas devem ser eliminadas para evitar a disseminaçăo do microrganismo. Outras medidas preventivas devem ser adotadas, como a eliminaçăo da pipetagem bucal, execuçăo de técnicas assépticas mais estritas no manuseio das células, controle dos soros de origem animal, da tripsina e de outros componentes dos meios de cultura utilizados em cultura celular. $O$ estudo mostrou que, ao invés das oito passagens seriadas propostas inicialmente, cinco foram suficientes para a detecçăo dos micoplasmas, o que representa economia de tempo e de materiais de custo elevado, reduzindo de 848 para 530 o número de passagens e a duraçăo do teste, de oito para cinco semanas.
\end{abstract}

DESCRITORES: Células cultivadas. Contaminaçăo, prevençăo. Micoplasma, isolamento.

\section{INTRODUÇĀO}

Desde que a introdução de antibióticos nos meios de cultivo de células minimizou o problema das contaminações bacterianas e fúngicas, os micoplasmas passaram a ser os contaminantes detectados com maior freqüência em células animais cultivadas "in vitro" para uso em virologia, em hibridização somática, na avaliação de toxicidade de materiais e outras, juntamente com os vírus latentes das células ${ }^{7}$ ou presentes em soros de origem animal.

A demonstração de contaminação de culturas celulares por micoplasmas foi feita pela primeira vez por Robinson e col. ${ }^{27}$, em fibroblastos humanos. Confirmado posteriormente por vários autores, o fato evidenciou que a presença de micoplasmas em linhagens celulares era evento extremamente comum ${ }^{8.9,17}$, podendo pertencer a cepas humanas, suínas ou bovinas ${ }^{1,3}$.

O tecido de origem das células, os meios de cultura comercializados usados em seu cultivo, a tripsina, os soros de origem bovi- na $^{1,2,3,4,8,12,17,19,20,28}$, o pessoal técnico que as repi$\mathrm{ca}^{33}$, assim como o aerosol que se forma por ocasião da tripsinização de garrafas de culturas de células contaminadas ${ }^{34}$, podem ser fontes de contaminação por micoplasmas, cuja presença acarreta, principalmente, alteraçðes metabólicas relacionadas com a arginina ${ }^{10,11,13,27,29,30,31} \mathrm{e}$ com o ácido nucléico $1,5,6,14,15,18,21,22,23,24,26$, alterações cromossômicas ${ }^{1,5,22,26}$ e interferência com a infecção e a replicação viral ${ }^{11,28}$. Necessário se torna, pois, manter controle de soros, tripsina e componentes dos meios de cultivo celular, no que se refere à presença de micoplasma. A alta incidência de contaminação nos soros bovinos $\mathrm{e}$ suínos $(57 \%)^{2}$, deve-se, principalmente, à falta de assepsia na coleta do sangue e na separação do soro e à esterilização imperfeita. Neste caso, formas viáveis de micoplasma, por serem pleomórficas, podem passar até mesmo pelos poros das membranas filtrantes de $220 \mathrm{~nm}$, porque estes podem ter seu diâmetro alterado quando grandes volumes são filtrados sob pressão $0^{2,9,33}$. Entretanto, o aquecimento dos soros de origem bovina, humana, suina e outras, a $56^{\circ} \mathrm{C}$ durante $30 \mathrm{~min}$, inativa os micoplasmas ${ }^{3}$.

* Seção de Cultura de Tecidos e Controle, Serviço de Virologia do Instituto Butantan - Av. Vital Brasil, 1500 - 05504 - São Paulo, SP - Brasil. 
Como este tipo de contaminantes não altera, necessariamente, a morfologia ou a cinética de multiplicação celular ${ }^{13,15}$; somente testes específicos possibilitam sua deteç̧ão, tais como o cultivo direto, a utilização de precursores radioativos pelas células infectadas, os testes enzimáticos, a coloração com anticorpos fluorescentes ou com corantes citoquímicos fluorescentes $^{10,16,23,25,32}$ e outros. É importante que, ao serem usadas, as culturas celulares estejam livres de micoplasmas porque os resultados de vários tipos de experimentos, quando realizados com células que os contém, devem ser avaliados com cautela ${ }^{4,20}$, por carecerem de confiabilidade. Uma vez identificadas as culturas celulares contaminadas, sua substituição por outras livres de micoplasma é altamente recomendável, já que seu manuseio, juntamente com culturas não contaminadas, geralmente ocasiona a disseminação deste microrganismo.

O presente estudo teve por objetivo investigar, no período de abril de 1983 a abril de 1988 , o nivel de contaminação por micoplasma existente em culturas celulares mantidas em laboratórios oficiais e particulares, com finalidades de pesquisa, diagnóstico, produção de preparaçōes-referência e produção e controle de vacinas a virus.

\section{MATERIAL E MÉTODO}

Células pesquisadas - Pertencentes a 29 linhagens celulares originárias de diferentes espécies animais, 106 amostras de culturas foram submetidas a testes visando o isolamento de micoplasma. Elas foram provenientes de sete laboratórios*. Em alguns casos, uma mesma linhagem foi recebida de mais de um laboratório e/ou foi testada em passagens diferentes. As espécies estudadas e seus respectivos tecidos de origem foram os seguintes:

1. Humana: KB (carcinoma epidermoide oral); HEp-2 (carcinoma epidermoide de laringe); HeLa (carcinoma epidermoide de cervix); HL e MRC-5 (pulmão de feto); WISH e AV-3 (amnion); RH (rim).

2. Cão: MDCK (rim).

3. Coelho: SIRC (córnea); RK-13 e RC (rim).

4. Camundongo: A-31 (embrião); Y-1 (tumor adrenal); NCTC-929 (tecido conectivo);
X-63 e SP-2 (mieloma); L-929 e McCoy (fibroblasto).

5. Hamster: BHK-21 (rim).

6. Macaco: LLC-MK (rim de Rhesus - Macaca mulatta); Vero, BS-C-1, BGM e GMK (rim de macaco verde . Cercopithecus aethiops).

7. Porco: PK-15 (rim).

8. Galinha: CER (embrião de pinto).

9. Boi: DBT (tecido diplóide); RV (rim de vitela).

As culturas foram recebidas de seus respectivos laboratórios em garrafas de cultura, formando monocamadas confluentes, ou em suspensão, ainda contidas nas ampolas de congelação. Foram então congeladas e descongeladas dez vezes no próprio recipiente, antes de serem semeadas nos meios de isolamento. $O$ cultivo das células em meio sem antibióticos, em pelo menos duas passagens antes do teste, é recomendável porque eles favorecem a formação de colônias de bactérias de forma " $L$ " que, por se assemelharem às colônias de micoplasma, dificultam sua detecção. Todavia, muitas .das amostras foram recebidas em meio com antibióticos.

Teste de detecção de micoplasma - Os testes foram realizados pelo método de cultivo direto, em anaerobiose, com a utilização do sistema Gaspak em jarras de policarbonato (Marca BBL), para fornecer o hidrogênio e o dióxido de carbono necessários ao isolamento. Um indicador específico de anaerobiose foi usado para a constatação desta condição?.

Alíquotas de $0,5 \mathrm{ml}$ da suspensão previamente congelada e descongelada de cada uma das amostras de células foram inoculadas em dois tubos de ensaio $(13 \times 130 \mathrm{~mm})$, contendo $4 \mathrm{ml}$ de meio líquido para micoplasma (Bacto-PPLO Broth w/o c.v. - DIFCO), suplementado com $20 \%$ de soro de cavalo e $10 \%$ de extrato de levedura9. Inicialmente, ao meio de um destes tubos foi adicionado $0,5 \%$ de glicose para ter seu desempenho comparado ao do segundo tubo, isento de glicose. Após incubação a $36,5^{\circ} \mathrm{C}$, em anaerobiose durante 7 dias, o conteúdo de cada tubo foi repicado para novo meio líquido, assim como para meio sólido contendo ágar purificado (Purified Agar OXOID), suplementado com $20 \%$ de soro de cavalo e $10 \%$ de extrato de

* Esses laboratórios pertencem ds seguintes instituições: Instituto Butantan, Instituto "Adolfo Lutz", Instituto Biológico, Instituto de Medicina Tropical da Faculdade de Medicina da Universidade de Sao Paulo, Companhia de Tecnologia e Saneamento Ambiental (CETESB), Instituto de Ciências Biomedicas da Universidade de Săo Paulo e Instituto de Química da mesma Universidade. 
levedura ${ }^{9}$, distribuído em placas de Petri de 4,5 $\mathrm{cm}$ de diâmetro. As placas contendo meio sólido foram inoculadas com $0,3 \mathrm{ml}$ e os tubos contendo meio líquido com $0,5 \mathrm{ml}$ do inóculo. $O$ procedimento descrito foi repetido por oito passagens sucessivas, sendo a incubação das placas e tubos feita em jarras de anaerobiose, a $36,5^{\circ} \mathrm{C}$. Leituras das placas foram feitas no 3 ? $^{\circ}$, $77^{\circ}, 14^{\circ}$ e $20^{\circ}$ dia, considerando-se como positivas aquelas em que se evidenciaram colônias de micoplasma do tipo ovo frito. Nos casos em que ocorreram dúvidas quanto a essa morfologia, elas foram submetidas à coloraçâo de Dienes'.

Controle positivo de micoplasma - A cepa USA-38502/56 de Mycoplasma gallisepticum* foi usada como inóculo para o preparo do micoplasma controle, lote-trabalho, a ser liofilizado. Para tal, $100 \mathrm{ml}$ de caldo PPLO foram inoculados com $6 \mathrm{ml}$ da $8^{\text {a }}$ passagem da cepa, comprovadamente positiva. Após 7 dias de incubação em anaerobiose, a cultura em suspensão foi centrifugada a $30.000 \mathrm{~g}$ durante $30 \mathrm{~min}$ em centrífuga SORVALL, modelo $\mathrm{RC}_{2}-\mathrm{B}$, refrigerada. O sedimento, ressuspenso em $10 \mathrm{ml}$ de caldo acrescido de $10 \mathrm{ml}$ de soro de cavalo, foi aliquotado em frascos $(0,5 \mathrm{ml}$ cada um). Após congelamento a $-70^{\circ} \mathrm{C}$ por $24 \mathrm{~h}$, foi liofilizado, selado e novamente estocado a $-70^{\circ} \mathrm{C}$. A liberação do lote-trabalho só ocorreu após a avaliação da viabilidade do produto liofilizado, por reconstituição e semeadura.

\section{RESULTADOS E DISCUSSÃO}

Na Tabela 1 são apresentados dados referentes às 106 amostras de culturas de células submetidas a testes de deteç̧ão de micoplasma. Deste total, 48 apresentaram-se positvas, o que representa indice de contaminação elevado $(45,28 \%)$ quando se consideram os efeitos negativos que o uso de tais culturas pode acarretar, pois causam alterações de vários tipos, podendo até interferir com a replicação viral, o que não pode ocorrer com células usadas em virologia. Foram testados 29 tipos de linhagens celulares. Destas, oito eram de origem humana e foram submetidas a 35 testes, dos quais 18 apresentaram-se positivos $(51,43 \%)$. Com as 21 linhagens remanescentes, originárias de outras espécies animais, foram realizados 71 testes, sendo 30 positivos $(42,25 \%)$.
A Tabela 2 apresenta dados que permitem correlacionar o número de passagens seriadas necessárias para o isolamento de micoplasmas à percentagem de positividade obtida nos testes das 106 amostras de culturas celulares, consideradas na pesquisa.

Considerando as 48 amostras de células que se revelaram portadoras de micoplasma, verificou-se que esta positividade foi determinada com número de passagens seriadas inferior ao que havia sido estabelecido para este estudo. Na Tabela 2 consta que $72,92 \%$ das amostras se positivaram com o aparecimento de colônias típicas em meio sólido no segundo repique, $20,83 \%$ no terceiro, $6,25 \%$ no quarto, e nenhuma do quinto ao oitavo repique. Como 4 passagens seriadas foram suficientes para evidenciar a presença do micoplasma, a proposta preliminar de se submeter cada amostra a 8 passagens poderá, de agora em diante, ser modificada para apenas 5 , do que resultarão economia de tempo, de meios de cultura e de outros reagentes de preço elevado. Aplicada a este estudo, teria significado uma diminuição do número de passagens seriadas de 848 para 530 , e do tempo de execução de cada teste, de 8 para 5 semanas. Poderá ser assegurada maior margem de segurança para este tipo de teste prolongando-o até 6 passagens.

$A$ adição de glicose ao meio líquido não influenciou os resultados dos isolamentos, indicando que os micoplasmas presentes nas células estudadas não necessitaram de meios mais enriquecidos para o seu desenvolvimento.

Para fazer face ao elevado índice de contaminação de células por micoplasma, os laboratórios que trabalham com culturas celulares deveriam adotar técnicas mais eficientes de assepsia, realizar cuidadosa desinfecção do local de trabalho e estimular seus técnicos a apresentarem bom nivel de higiene pessoal pois, comprovadamente, o micoplasma faz parte da microbiota oral humana ${ }^{33}$, sendo responsável por $42 \%$ das contaminações celulares, como foi demonstrado em laboratórios americanos ${ }^{2}$. A pipetagem bucal deve ser completamente abolida e a utilização de capelas de fluxo laminar ou de áreas providas de filtros de ar, de elevada eficiência, também poderão contribuir para diminuir o risco de contaminação.

O desenvolvimento da presente pesquisa revelou que, embora a maioria dos usuários de culturas celulares esteja ciente do sério problema representado pelos micoplasmas ${ }^{9,17,20,29}$, um

* Cepa cedida pelo Laboratório de Microbiologia da Faculdade de Medicina Veterinária e Zootecnia da Universidade de Sào Paulo. 
TABELA 1

Incidência de contaminação por micoplasma observada em 106 testes de linhagens celulares, através do teste de cultivo direto. São Paulo, 1983-1988.

\begin{tabular}{|c|c|c|c|c|}
\hline \multicolumn{2}{|c|}{ Linhagem Celular } & \multirow{2}{*}{$\begin{array}{c}\text { No de Amostras } \\
\text { Testadas }\end{array}$} & \multicolumn{2}{|c|}{ Resultado } \\
\hline Origem & Nome & & Positivo & Negativo \\
\hline $\mathbf{H}$ & AV -3 & 5 & 3 & 2 \\
\hline $\mathrm{U}$ & HeLa & 4 & 2 & 2 \\
\hline $\mathbf{M}$ & Hep-2 & 18 & 8 & 10 \\
\hline A & $\mathrm{HL}$ & 1 & 0 & 1 \\
\hline $\mathbf{N}$ & $\mathbf{K B}$ & 3 & 2 & 1 \\
\hline \multirow[t]{3}{*}{ A } & MRC-5 & 1 & 0 & 1 \\
\hline & $\mathbf{R H}$ & 2 & 2 & 0 \\
\hline & WISH & 1 & 1 & 0 \\
\hline Total & 8 & 35 & $18(51,43 \%)$ & $17(48,57 \%)$ \\
\hline 0 & $A-31$ & 1 & 0 & 1 \\
\hline $\mathrm{U}$ & BGM & 2 & 2 & 0 \\
\hline $\mathrm{T}$ & BHK-21 & 13 & 6 & 7 \\
\hline $\mathbf{R}$ & BS-C-1 & 3 & 3 & 0 \\
\hline A & CER & 1 & 0 & 1 \\
\hline \multirow{2}{*}{ s } & DBT & 1 & 0 & 1 \\
\hline & $\mathrm{GMK}_{2}$ & 1 & 0 & 1 \\
\hline E & L.929 & 2 & 2 & 0 \\
\hline $\mathrm{s}$ & LLC-MK 2 & 8 & 4 & 4 \\
\hline $\mathbf{P}$ & McCoy & 2 & 0 & 2 \\
\hline$\dot{E}$ & MDCK & 3 & 0 & 3 \\
\hline C & NCTC -929 & 1 & 0 & 1 \\
\hline I & PK-15 & 2 & 2 & 0 \\
\hline $\mathrm{E}$ & $\mathbf{R C}$ & 2 & 0 & 2 \\
\hline \multirow{7}{*}{$\mathrm{S}$} & RK-13 & 2 & 1 & 1 \\
\hline & RV & 1 & 0 & $i$ \\
\hline & SIRC & 4 & 2 & 2 \\
\hline & SP-2 & 6 & 3 & 3 \\
\hline & Vero & 12 & 2 & 10 \\
\hline & $X-63$ & 1 & 1 & 0 \\
\hline & $\mathrm{Y}-1$ & 3 & 2 & 1 \\
\hline Total & 21 & 71 & $30(42,25 \%)$ & $41(57,75 \%)$ \\
\hline Total Geral & 29 & 106 & $48(45,28 \%)$ & $58(54,72 \%)$ \\
\hline
\end{tabular}

\section{TABELA 2}

Percentagem de positividade verificada em 106 testes de deteç̧ão de micoplasma, em função do número de passagens seriadas necessárias ao isolamento. Sāo Paulo, 1983-1988.

\begin{tabular}{|c|c|c|}
\hline $\begin{array}{c}\text { No de Passagens } \\
\text { Seriadas }\end{array}$ & $\begin{array}{l}\text { Resultado } \\
\text { Positivo }\end{array}$ & $\begin{array}{c}\text { Positividade } \\
\%\end{array}$ \\
\hline $\begin{array}{l}2 \\
3 \\
4 \\
5 \\
6 \\
7 \\
8\end{array}$ & $\begin{array}{r}35 \\
10 \\
3 \\
0 \\
0 \\
0 \\
0\end{array}$ & $\begin{array}{c}72,92 \\
20,83 \\
6,25 \\
0 \\
0 \\
0 \\
0\end{array}$ \\
\hline Total & 48 & 100 \\
\hline
\end{tabular}

número menor do que se previra se interessou em saber se suas culturas estavam contaminadas ou não, colaborando com o envio de amostras de culturas. Alguns preferiram omitir-se, deixando de enviar amostras, talvez receando alguma repercussão negativa caso os testes viessem a revelar a presença do microrganismo. $O$ número de 106 amostras coletadas num periodo relativamente longo, (1983-1988) é significativo e reforça estas considerações.

A técnica adotada demonstrou ser prática e efetiva para a detecção de micoplasmas presentes em células cultivadas "in vitro". Sua implantação em caráter de rotina é, pois, recomendada para laboratórios cujo trabalho depende do uso de culturas celulares, aos quais interessam dados experimentais ou de produção, não comprometidos pela presença destes contaminantes. 
AGRADECIMENTOS

Ao Professor Doutor Antonio Joaquim Rossini, do Departamento de Medicina Veterinária e Preventiva de Saúde Animal da Faculdade de Medicina Veterinária e Zootecnia da Universidade de São Paulo, pela orientação relativa à técnica adotada para os isolamentos.

MJYAKI, C. et al. [Mycoplasma contamination of cell cultures maintained in laboratories of private, government and college institutions]. Rev. Saúde públ., S. Paulo, 23:39-44, 1989.

ABSTRACT: Mycoplasma is one of the most serious contaminants of cell cultures. Its detection is very important in virology, as well as its eradication. The aim of this study was to verify the incidence of mycoplasma in cell lines maintained in seven laboratories of private, government and college institutions of the State of São Paulo, Brazil, for the purposes of research, production of reagents for diagnosis and production of biologicals for human and animal use. Of the 29 cell lines, eight were derived from human tissues and 21 from other animal species (dog, rabbit, mouse, hamster, monkey, pig, chicken and ox). Using the direct method with specific liquid and solid media for detection of mycoplasma, 48 out of the 106 cell samples tested were positive, corresponding to a contamination index of $45.28 \%$. The incidence of contamination among the 35 cell samples of human origin was $51.43 \%$ ( 18 positive). Of the 71 samples originated from other species, 30 were positive $(42.25 \%)$. The high incidence of contamination found calls for the adoption of measures for the prevention of this hazard: the elimination of mouth pipetting, the use of aseptic techniques and a rigid control of trypsin, serum and other components of cell culture media. The substitution of mycoplasma-free cultures for all contaminated ones and the performance of periodical tests for mycoplasma detection must also be carried out to prevent and avoid the dissemination of these organisms. Data obtained showed that contamination appeared in the $2^{\text {nd }}\left(\mathbf{7 2 . 9 2 \% )}\right.$, in the $3^{\text {ro }}$ $(20.83 \%)$ and in the $4^{\text {th }}$ passage $(6.25 \%)$. By using this technique, five passages are sufficient to detect mycoplasma and allow a safety margin, thus shortening the length of the test, saving reagents and providing satisfactory and reliable results. If a similar study were carried out establishing five as the number of serial passages for each mycoplasma detection test, the original number of passages would be reduced from 848 to $\mathbf{5 3 0}$ and the time spent on the test would be reduced from eight weeks to five.

KEYWORDS: Cells, cultured. Contamination, prevention. Mycoplasma, isolation.

\section{REFERENCIAS BIBLIOGRÁFICAS}

1. BARILE, M.F. Mycoplasma and cell cultures. Nat. Cancer Inst. Monogr., 29:201-4, 1968.

2. BARILE, M.F. Mycoplasma contamination of cell cultures: incidence, source, prevention, and problems of elimination. In: Kruse Jr., P.F., \& Patterson Jr., N.K., eds. Tissue cultures methods and applications. New York, Academic Press, 1973. p.729. 35.

3. BARILE, M.F. \& KERNE, J. Isolation of Mycoplasma arginini from commercial bovine sera and its applications in contaminated cell cultures. Proc. Soc. exp. Biol. Med., 138:432-7, 1971.

4. BARILE, M.F.; MALIZIA, W.F.; RIGGS, D.B. Incidence and detection of pleuropneumonia - like organisms in cell cultures by fluorescent antibody and culture procedures. J. Bact., 84:130-6, 1962.

5. CORIELL, L.L.; FABRIZIO, D.P.; WILSON, S.R. Comparison of pleuropneumonia-like organism strains from tissue culture by complement fixation. Ann. N.Y. Acad. Sci., 79:574-80, 1960.

6. FOGH, J. \& FOGH, H. Chromosome changes in PPLO infected FL Human amnion cells. Proc. Soc. exp. Biol. Med., 119:233-8, 1965.

7. HAKALA, M.T.; HOLLAND, J.P.; HOROSZEWICZ, J.S. Change in pyrimidine deoxyribonucleoside metabolism in cell culture caused by mycoplasma (PPLO) contamination. Biochem. Biophys. Res. Commun., 11:466-71, 1963.
8. HAYFLICK, L. A comparison of primary monkey kidney, heteroploid cell lines, and human diploid cell strains for human virus vaccine preparation. Amer. Rev. resp. Dis., 88:387-93, 1963.

9. HAYFLICK, L. Tissue cultures and mycoplasmas. Texas Rep. Biol. Med., 23(Suppl. 1):285-303, 1965.

10. HAYFLICK, L. \& CHANOCK, R.M. Mycoplasma species of man. Bacteriol. Rev., 29:185-221, 1965.

11. KAPLAN, D.R.; HENKEL, T.J.; BRACIALE, V.; BRACIALE, F.J. Mycoplasma infection of cell cultures: tymidine incorporation of culture supernatants as a screening test. J. Immunol., 132:9-11, 1984.

12. KENNY, G.E. \& POLLOCK, M.E. Mammalian cell cultures contaminated with pleuropneumonia - like organisms. I. Effect of pleuropneumonia - like organisms in growth of established cell strains. $J$, infect. Dis., 112:7-16, 1963.

13. KIHARA, K.; ISHIDA, A.; OKUMURA, W. Detection of mycoplasmal contaminants in sera. $J$. Biol. Stand., 9:243-51, 1981.

14. KRAEMER, P.M. Mycoplasma (PPLO) from covertly contaminated tissue cultures: differences in arginime degradation between strains. Proc. Soc. exp. Biol. Med., 117:910-8, 1964. 
15. LEVINE, E.M.; BURLEIGH, I.G.; BOONE, C.W.; EAGLE, H. An altered pattern of RNA synthesis in serially propagated human diploid cells. Proc. Nat. Acad. Sci. USA, 57:431-8, 1967.

16. LEVINE, E.M.; THOMAS, L.; MCGREGOR, D.; HAYFLICK, L.; EAGLE, H. Altered nucleic acid metabolism in human cell cultures infected with mycoplasma. Proc. Nat. Acad. Sci. USA, 60:583-9, 1968.

17. McGARITY, G.J. Detection of contamination. In: Jakoby, W.B. \& Pastan, I.H., eds. Methods in enzymology. New York, Academic Press, 1979. v.58, p.18-28.

18. MACPHERSON. I. Mycoplasmas in tissue culture. $J$. Cell Sci., 1:145-68, 1966.

19. NARDONE, R.M.; TODD, J.; GONZALEZ, P.; GAFFNAY, E.U. Nucleoside incorporation into strain L cells: inhibition by pleuropneumonia - like organisms. Science, 149:1100-1, 1965.

20. NELSON, J.B. Biology of the pleuropneumonia like organisms. Discussion of part II. Ann. N.Y. Acad. Sci., 79:458-60, 1960.

21. O'CONNELL, R.C.; WITTLER, R.G.; FABER, J.E. Aerosols as a source of indespread mycoplasma contamination of tissue cultures. Appl. Microbiol., 12:337-42, 1964.

22. OSTERHAUS, A. \& UYTDEHAAG, F. Lymphocyte Hybridomas: production and use of monoclonal antibodies. In: Spier, R.E. \& Griffits, J.B., eds. Animal cell biotechnology. London, Academic Press, 1985, v.2, p.49-69.

23. PATON, G.R.; JACOBS, J.B.; PERKINS, F.T. Chromosome changes in human diploid cell cultures infected with mycoplasma. Nature, 207:43-5, 1965.

24. POLAK-VOGLLZANG, A.A. Mycoplasmatales in cell cultures: detection and control. Amsterdan, 1983. [Thesis]
25. RANDALL, C.C.; GAFFORD, L.G.; GENTRY, G.A.; LAWSON, L.A. Liability of host-cell DNA in growing cell cultures due to mycoplasma. Science, 149:1098-9, 1965.

26. READING, C.L. Theory and methods for immunization in culture and monocional antibody production. J. immunol. Methods, 53:261-91, 1982.

27. ROBINSON, L.B.; WICHELBRAUSEN, R.H.; RAZINAN, B. Contamination of human cell cultures by pleuropneumonia organisms. Science, 124:1147-8, 1956.

28. ROTHBLATT, G.H. PPLO contamination in tissue cultures. Ann. N.Y. Acad. Sci., 79:430-2, 1960.

29. ROUSE, H.; BONIFAS, W.; SCHLESINGER, R. Dependence of adenovirus replication on arginine and inhibition of plaque formation by pleuropneumonia - like organisms. Virology, 20:357-65, 1963.

30. SCHIMKE, R.T. Studies on metabolism of arginine by mycoplasma. Ann. N.Y. Acad. Sci., 143:573-7, 1967.

31. SCHIMKE, R.T. \& BARILE, M.F. Arginine metabolism in pleuropneumonia - like organisms isolated from mammalian cell cultures. J. Bacteriol., 86:195$206,1963$.

32. SCHIMKE, R.T. \& BARILE, M.F. Arginine breakdown in mammalian cell cultures contaminated with pleuropneumonia - like organisms (PPLO). Exp. Cell Res., 30:593-6, 1963.

33. STANBRIDGE, E. Mycoplasma and cell cultures. Bacteriol. Rev., 33:206-27, 1971.

34. STANBRIDGE, E.J. \& SCHEIDER, E.L. The need for non-cultural methods for the detection of mycoplasma contaminants. Dev. Biol. Stand., 37:191-200, 1977.

Recebido para publicaçđo em 17/6/1988.

Reapresentado em $17 / 11 / 1988$.

Aprovado para publicaçäo em 18/11/1988. 